\title{
DELIBERATION OF HILLY AREAS FOR WATER HARVESTING APPLICATION IN WESTERN CRETE, GREECE
}

\section{ELHAG M.* \\ BAHRAWI J.A.}

Received: $11 / 12 / 2015$

Accepted: 30/03/2016

Available online: $24 / 06 / 2016$

\author{
Department of Hydrology and Water Resources Management \\ Faculty of Meteorology, Environment and Arid Land Agriculture \\ King Abdulaziz University, Jeddah, 21589, Kingdom of Saudi Arabia
}

\section{ABSTRACT}

The meteorological, physical and hydrological conditions prevailing in a hilly area, namely the region around Malaxa (Western Crete), are analyzed and investigated in relation to water harvesting applications. The literature relating to water harvesting techniques and applications is reviewed and the conclusions that have been drawn by other investigators concerning methods of water harvesting techniques and applications are outlined and discussed. Specific reasons for choosing this particular study area was given and the types and installation of equipment used are also described. The results indicate that despite the fact that the mean annual rainfall can be considered as high $(940 \mathrm{~mm})$, its distribution is very uneven and only $6 \%$ of it falls from May to September. This fact creates serious water problems in the area during the dry seasons. Also, mean annual and monthly average temperatures have values which contribute to the evapotranspiration of high amount of precipitation and may form frost and overland flow respectively, during some days. Furthermore, the annual runoff is estimated to be $248 \mathrm{~mm}$ and a part of this can be overland flow while the other part can be a throughflow. The occurrence of overland flow is also proved by the comparison of the infiltration and the intensities of rainfall with the return periods of 5 and 10 years. Additionally, the quantification of overland flow is made by collecting and analyzing it from experimental plots. By this method, we clarified that the quantity of overland flow is affected by the inclination of the ground, the density of vegetation and the compaction of the soil. These results, although all of them are not wholly conclusive, can present an advance for understanding the use of meteorological, physical and hydrological conditions for water harvesting applications in an area.

Keywords: Hydrology, Meteorological Elements, Physical Phenomena, Rain and Water Balance, Runoff, Water Harvesting

\section{Introduction}

Water harvesting is a very old technique used for obtaining water for irrigation, domestic uses, livestock watering and all the human needs (Al-Charideh, 2012). Specifically, the development of this technique started with the cultivation of the land by man and mainly when he faced serious problems due to uneven distribution of precipitation through the year and during the severe and prolonged droughts.

Elhag M. and Bahrawi J.A. (2016), Deliberation of hilly areas for water harvesting application in Western Crete, Greece, Global NEST Journal, 18(3), 621-629. 
The rainwater harvesting techniques developed in the last decades could be divided into the following two main categories according to Boers and Ben-Asher, (1982) and Udawattage, (1985) are Micro-Catchment Water Harvesting (MCWH), and Runoff Farming Water Harvesting (RFWH). MCWH is a method of collecting surface runoff (overland flow) from a Contributing Area (CA) over a flow distance of less than $100 \mathrm{~m}$ and storing it for consumptive uses in the root zone of an adjacent Infiltrating Basin (IB), (Boers and Ben Asher, 1982). Runoff Farming Water Harvesting is defined as a method of collecting surface runoff from a Catchment Area (CA), with the use of channels, dams, or diversion systems and storing it in a Surface Reservoir (SR) or in the root-zone of a Farmed Area (FA) for direct consumptive use, such as the irrigation of the adjacent area (Boers and Ben-Asher, 1982). Also, RFWH without SR is considered to be a Runoff Farming System.

In $\mathrm{MCWH}$, it is very important to decrease the infiltration of the soil in the $\mathrm{CA}$ in order to increase the surface runoff. For this reason, considerable research has been conducted on the vegetation management of the CA, its surface treatment and mainly its chemical treatment. Specifically, a number of studies conducted in various countries of the world have shown that surface runoff can be increased by vegetation management in areas where the annual amount of precipitation is higher than $280 \mathrm{~mm}$ (Cooley et al., 1976). For smoothed catchments, runoff efficiencies ranged from 20-35\% (Fink et al., 1980; Frasier, 1980). But it was difficult to draw final conclusions because runoff efficiency depends on the antecedent soil moisture, storm intensity, and duration, catchment size and number of post-treatment years (Fink et al., 1980; Holder, 2004).

The main disadvantage of RFWH technique is the necessary investment for the construction of SR and the necessary system for the distribution of water from the SR to the cultivated fields. The accomplishment of RFWH application relies chiefly upon two main factors: the rainfall distribution throughout the growing phase of the crops, and the availability of soil profile, which could store adequate quantities of water (Chowdhury et al., 2010).

The aim of this research work is to investigate climatic, physical and hydrological conditions of hilly areas of the western part of Crete for determining any occurrence of overland flow which is an essential procedure for planning and construction of water harvesting techniques.

\section{Materials and Methods}

\subsection{Study area}

The work reported in this scholarly work was carried out in the upper part of the hills of Chania, in the western part of Crete and near a village called Malaxa. The underlying reasons for this selection are: The information about the runoff (overland flow) occurrence in this zone is of paramount importance. This is because annual rainfed crops and fruit trees constitute the bulk of the cultivated crops, and the production of them could increase if the quantity of water would be conserved for irrigation during the growing season and the dry period. The area is typical for many other upland areas of Chania and generally of Crete in terms of relief and land use. The mean altitude is $395 \mathrm{~m}$ above the sea level (a.s.l). The gradient ranges from $50 \%$ (on the lower slopes) to $10 \%$ (on the upper slopes) and it is much higher in the slopes further down of the study area. The general aspect is North to Northeast, but there is a large number of small areas (slopes) with different aspects. The mean annual precipitation from the year 2000 to 2010 is $940.5 . \mathrm{mm}$. The mean annual temperature is $17.6^{\circ} \mathrm{C}$, therefore, the climate of the study area, based on $\mathrm{Q}$ index value; is characterized as sub-humid with cold winters (Kyriakakis, 1993). The soil of the selected catchment under study is derived from limestone and dolomites and is characterized by clay to clay-loamy texture. The dominant vegetation in the study area is phryganic, which is intermixed with herbaceous species. The annual are the most numerous (legumes and grasses), and they usually grow in winter and dry up in May. The perennials leaf grows in winter, flower in spring, and dry up in summer. Other perennials, mainly the grasses, persist throughout the year (Kyriakakis, 1993; Brauman et al., 2010). 


\subsection{Experimental design}

This investigation was carried out by collecting data on precipitation and temperature in order to study their characteristics and for estimating the various components of the water balance equation of the area and mainly for estimating the component of runoff. Furthermore, it was taken into consideration that any occurrence of overland flow could be detected and estimated by comparing the intensities of the precipitation in the area with the infiltration rates of the soil, or by direct measurement of the overland flow.

The infiltration rate of the soil can be affected by the physical properties, the vegetation species and its coverage. For these reasons it was decided to take soil samples for analysis and to collect and identify the various vegetative species growing in the study area. 30 soil samples were taken from the study area to the depth of $20 \mathrm{~cm}$.

\subsection{Detection occurrence of surface runoff}

Apparently, occurrence of runoff and mainly occurrence of surface runoff in a given area is necessary for the application of water harvesting techniques. Runoff can be generally determined by measuring it directly in the field or indirectly by various methods such as the water balance approach. Water balance equation has generally the following form:

$$
\mathrm{P}=\mathrm{Q}+\mathrm{EV}+\Delta \mathrm{S}
$$

Where:

$\mathrm{P}=$ Precipitation of the area, in $\mathrm{mm}$.

$Q=$ Runoff of the area, in $\mathrm{mm}$.

$\mathrm{EV}=$ Evapotranspiration of the area, in $\mathrm{mm}$

$\Delta S=$ Amount of water stored in the soil (soil moisture).

The last parameter $(\Delta \mathrm{S})$ for a specific area and on a yearly basis practically remains constant. So the former equation can be written as follows:

$$
\mathrm{Q}=\mathrm{P}-\mathrm{EV}
$$

Consequently, runoff can be determined from the quantity of precipitation $P$ and evapotranspiration (EV). From these two parameters, only precipitation data were available. So, for the calculation of the evapotranspiration it was decided to apply an appropriate method for the study area. Based on Dune and Leopold (1978) findings, the Thornthwaite and Turc's formula was implemented in the current study. This was due to the fact that the mentioned formulas need only mean monthly temperature data, which have been already estimated.

The Thornthwaite formula has the following form:

$$
E_{t}=1.6\left[\frac{10 T_{\alpha}}{1}\right]^{2}
$$

Where:

$\mathrm{Et}=$ potential in $\mathrm{Cm} /$ month.

Ta=mean monthly air temperature $\left({ }^{\circ} \mathrm{C}\right)$

$\mathrm{I}=$ annual heat index which is expressed by the following formula: 
$\mathrm{I}=\sum_{\mathrm{i}=1}^{12}\left[\frac{\mathrm{T}_{\mathrm{aj}}}{5}\right]^{1.51}$

Where:

$a j=a$ coefficient, given by the equation: $a=0.49+0.01179 \mid-0.0000771 I^{2}+0.000000675 I^{3}$.

I was calculated to be equal to 65.7 then the a-coefficient was calculated to be equal to 1.524 . The values of I and aj as well as the mean temperature of each month were applied and the potential evapotranspiration for each month in the study area was calculated.

At this point it must be mentioned that the monthly potential evapotranspiration, computed by the Thornthwaite equation is for a standard month of 360 hours of daylight. Hence, the calculated values must be adjusted for the number of days per month and the length of day. The monthly potential evapotranspiration adjusted values of for the designated study area was calculated to be $752 \mathrm{~mm}$.

\subsection{Calculation of the water balance of the study area}

The water balance of the study area was calculated by the referred equation: $Q=P-E T$, where $P=940 \mathrm{~mm}$ and $E T=752 \mathrm{~mm}$. So, the annual amount of runoff (overland flow and throughflow) was $940-752=188 \mathrm{~mm}$. This amount of runoff is the mean value of 27 years and may have been different if information about the value of the actual evapotranspiration had been available. Due to this lack of information, the mentioned parameter was calculated by applying an empirical formula developed by Turc in 1954. Turc's formula is written as following:

$$
\mathrm{ET}=\frac{\mathrm{P}}{\left[0.09+\left(\frac{\mathrm{P}}{\mathrm{EPI}}\right)^{2}\right]^{0.5}}
$$

Where:

$\mathrm{P}=$ the sum of annual precipitation $(\mathrm{mm})$,

$\mathrm{EPI}=$ an index given by the following formula

$\mathrm{PI}=300 * 25 \mathrm{~T}+0.05 \mathrm{~T}^{3}$

Therefore:

$\mathrm{ET}=\frac{940.5}{\left[0.09+\left(\frac{940.5}{847.9}\right)^{2}\right]^{0.5}}=\frac{940.5}{1.4346}=655.6$

Finally, this formula shows that the actual evapotranspiration is smaller than the potential evapotranspiration by $752-656=96 \mathrm{~mm}$. Therefore, runoff can be estimated by the following operation:

Runoff $=940.5-655.6=284.9 \mathrm{~mm}$

Except for the annual amount of evapotranspiration, it is important to investigate its the distribution throughout the whole year. Details about this are presented in Table 1, in which for reasons of convenience, the potential instead of the actual evapotranspiration, has been used.

Precipitation is higher than actual evapotranspiration for seven months (January, February, Mars, April, October, November and December), and there is soil moisture deficit for the remaining five months. These months coincide with the dry period, consequently, the quest for effective water conservation strategy during this period is highly appreciated. The calculated amount of runoff is concerned ( $284 \mathrm{~mm})$, part of it may occur in the form of overland flow and a part of it in the form of throughflow. These two quantities are difficult to be separated. 


\subsection{Application of tracer on the surface of the plots}

Visual marker in term of specific fluorescent dust was applied on the experimental plots. The next step was to make observation about the marker movements from the called "tested area" to the "control area". The lower part of the plots was divided into two different areas: one was used for the application of fluorescent dust (tracer), while the second was used as a control area to detect any movement of this substance by rainwater after any rainfall event. However, the detection of any existent tracer in the control area was made after a rain event for evidence of overland flow.

Fluorescein Disodium Salt: $\mathrm{C}_{20} \mathrm{H}_{10} \mathrm{Na}_{2} \mathrm{O}_{5}$ was considered to be good for testing the occurrence of overland flow in the study area (Gehrels, 2000). The listed substance, when it coming in contact with water, shows fluorescent green markers on the ground surface, and this facilitates the detection of the movement of rainwater and mainly surface runoff.

\subsection{Installation of gutters and collection of surface runoff}

The second method consisted of the collection of any possible volume of overland flow occurring on the ground surface after a certain period of rainfall gutters connected to tanks were used to collect any surface runoff. Engelhardt et al., (2013) used such a technique for the construction of the plots and the installation of gutters. The gutters were made of light zinc and bent to an angle of $45^{\circ}$. They were inserted so that water flowing into the gutters would flow from there into a polythene container ( 50 liters). The gutters were driven 3-4 cm into the plot face in such a way that almost all overland flow would be collected in the tank which were $5 \mathrm{~cm}$ below the ground surface. Any water loss from the surface plots was regarded as negligible due to the plot gradient and the shape of the plot surface. When the construction was finished, a roof was built to prevent rain falling directly on the containers and the gutters.

\section{Results and Discussion}

January is the wettest month with $188.8 \mathrm{~mm}$ and July the driest with $1.3 \mathrm{~mm}$ of rainfall. The distribution of the annual precipitation is very uneven and a small amount falls during the growing season and mainly during the summer.

The annual values of precipitation ranges from $532.2 \mathrm{~mm}$ in 2008 (very dry) to $1223 \mathrm{~mm}$ in 1994 (very wet). This range and the large standard deviation reveal that dry and wet years may occur randomly and definitely they do not occur after a specific period of time (in cycles). Consequently, it is very important to know at least the probability occurrence of any year with any specific amount of rainfall. Specifically, the annual values of precipitation were ranked from the smallest $(532.2 \mathrm{~mm}$ has a rank of $\mathrm{m}=1)$ to the largest $(1223 \mathrm{~mm}$ with $m=27$. The cumulative frequency of the years with rainfall equal or less than the particular annual rainfall, this means that only $2.3 \%$ of the annual amount of rainfall is equal to or lower than $532 \mathrm{~mm}$ and $96.4 \%$ equal to or lower than $1223 \mathrm{~mm}$.

Reading across the best-fit line $(Y=0.1607 X-101.18)$, the $50 \%$ value on the ordinate gives a mean annual rainfall of $939 \mathrm{~mm}$, and it is more or less close to the previous one $940.5 \mathrm{~mm}$. Reading across to the line from the 16- and 84-percent values on the ordinate yields respectively: $703 \mathrm{~mm}$ and $1148 \mathrm{~mm}$ on the abscissa. Each of these values lies one standard deviation away from the mean the standard deviation, therefore, is approximately $209 \mathrm{~mm}$. The driest year of $532.2 \mathrm{~mm} \mathrm{(2008)} \mathrm{has} \mathrm{a} \mathrm{return} \mathrm{period} \mathrm{of} \mathrm{T=} 28$ years, and the probability of occurrence of this amount of precipitation during any year is $3.6 \%$. The second driest year (2003 with $582 \mathrm{~mm}$ ) has a return period of $\mathrm{T}=14$ years and the probability of occurrence of this amount of precipitation during any year is $7.14 \%$. The monthly potential evapotranspiration was then computed by the Thornthwaite equation for a standard month of 360 hours of daylight.. Hence, the calculated values must be adjusted for the number of days per month and the length of day. The corrected values of the monthly 
potential evapotranspiration value of the study area were calculated in $752 \mathrm{~mm}$. The water balance of the study area was calculated to be $P=940 \mathrm{~mm}$ and $E T=752 \mathrm{~mm}$. So, the annual amount of runoff (overland flow and throughflow) was $188 \mathrm{~mm}$. This amount of runoff is the mean value of 27 years and may have been different if information about the value of the actual evapotranspiration had been available. Finally, the actual evapotranspiration is smaller than the potential evapotranspiration by $96 \mathrm{~mm}$.

The infiltration capacity of the soil in all the plots had at the beginning a maximum value of 198, 120 and 108 $\mathrm{mm} / \mathrm{hr}$ for plots I, II and III respectively and then it decreased gradually with time. Actually, the correspondent values after the application of water for one hour were 45, 17 and $12 \mathrm{~mm} / \mathrm{hr}$ respectively. In addition to the above, infiltration capacities (values) must in reality be lower due to the disturbance of the soil by the cylinder, the lateral movement of water in the soil (Rink et al., 2012)

The rainfall intensities for the study area were necessary in order to compare them with the presented infiltration capacities of the soil. The rainfall intensities were calculated from data of the Souda station, which is close to the study area. This decision was taken due to the lack of rainfall intensities for our area. Specifically, the intensities with a return period of 5 and 10 years and with duration from 5 to 60 minutes were calculated. These values were increased by $10 \%$, because the study area has a higher altitude.

The comparison between the two above parameters is presented as well in Fig. 1 (a) and Fig. 1(b). In Fig. 1 (a), a comparison is made between the mean infiltration capacity of the three plots and the mentioned intensities of rainfall. It becomes clear that the intensities of rainfall are much higher than the infiltration capacities. This difference is even higher between the two parameters when the mean infiltration capacity of plots II and III are used Fig. 1(b).

Table 1. Calculation of the water balance

\begin{tabular}{cccccc}
\hline Months & $\begin{array}{c}\text { Mean monthly } \\
\text { precipitation } \\
(\mathbf{m m})\end{array}$ & $\begin{array}{c}\text { Mean monthly actual } \\
\text { evapotranspiration } \\
(\mathbf{m m})\end{array}$ & Difference & $\begin{array}{c}\text { Cumulative } \\
\text { deficit }(\mathbf{m m})\end{array}$ & $\begin{array}{c}\text { Surplus } \\
\text { precipitation } \\
(\mathbf{m m})\end{array}$ \\
\hline January & 188 & 16.5 & 171.5 & - & 171.5 \\
\hline February & 162 & 17.4 & 144.6 & - & 144.6 \\
\hline March & 122 & 24.3 & 97.7 & - & 97.7 \\
\hline April & 49 & 41.8 & 7.2 & - & 7.2 \\
\hline May & 14 & 68.0 & -54.0 & 54.0 & - \\
\hline June & 5 & 98.4 & -93.4 & 93.4 & - \\
\hline July & 1 & 109.7 & -108.7 & 108.7 & - \\
\hline August & 5 & 101.0 & -96.0 & 96.0 & - \\
\hline September & 33 & 75.8 & -42.8 & 42.8 & - \\
\hline October & 103 & 52.2 & 50.8 & - & 50.8 \\
\hline November & 121 & 31.4 & 89.6 & - & 89.6 \\
\hline December & 138 & 19.1 & 118.9 & - & 118.9 \\
\hline Total & 941 & 655.6 & - & 394.9 & 680.3 \\
\hline
\end{tabular}

The difference between the calculated intensities of rainfall with return periods 5 and 10 years and the infiltration capacities of the soil is very high and definitely there are at least some rain events every year which produce overland flow. This was detected during the field work when tracers were used and occurrence of overland flow was quantified by collecting it in containers.

Fluorescein Disodium Salt $\left(\mathrm{C}_{20} \mathrm{H}_{10} \mathrm{Na}_{2} \mathrm{O}_{5}\right)$ was used and spread in the plots when it was about to rain (Table 2). The tracer was spread with the same way and density in the middle area of all the plots and so any occurrence of overland flow could remove and sweep away the tracer in the lower part of the plots (in the C.a). By this way not only the occurrence, but also the expansion of overland flow could be detected. 
The tracer was swept away in both the plots of pairs I and II and in the first plot of pair III. This movement of the tracer was due to the occurrence of overland flow, Both "green areas" of the plots in pair I were almost of the same size, so we can say that the partial removal of vegetation may not have affected the quantity of overland flow. The "green areas" were also the same in the plots of the second pair, despite the removal of half of the vegetation in the second plot of this pair. As far as the plots of the third pair are concerned, "Green area" was observed only in the first plot of them and actually it's the one without any treatment of vegetation. From these observations, there was no clear indication if the treatment of vegetation had affected the occurrence of overland flow (Brauman et al., 2010).

Comparing the expansion of the "Green area" in the plots of the two first pairs, it's observed that they are larger in the first than in the second pair. An explanation of this difference can be given if we take into account the slope (50\%) of the plots in pair I. The importance of this parameter for the occurrence of overland flow is also evident from the expansion of the "green areas" in both the plots of the second pair, as some decrease of the slope (35\%) results to the decrease of the "Green area" as well. As far as the plots of the third pair are concerned, overland flow occurred in the plot were no vegetation treatment was made. However, the "Green area" was smaller than in the previous plots and except for the lower slope (21\%), it was difficult to find out which other factors may have affected the response of this plot to the rain event studied.

Table 2. Observed Results in the Experimental Plots

\begin{tabular}{|c|c|c|c|}
\hline Location $\mathbf{N}^{\circ}$. & Plot $N^{\circ}$. & $\begin{array}{l}\text { Physical condition and surface treatment within } \\
\text { the plots }\end{array}$ & $\begin{array}{l}\text { Observed } \\
\text { results* }\end{array}$ \\
\hline \multirow{8}{*}{ Plots in location (I) } & \multirow{4}{*}{ I N } & Slope: $50 \%$ & \multirow{4}{*}{+++} \\
\hline & & General Orientation: $75^{\circ}$ & \\
\hline & & Specific Orientation: $390^{\circ}$ & \\
\hline & & Natural vegetation & \\
\hline & \multirow{4}{*}{ IT } & slope: $50 \%$ & \multirow{4}{*}{+++} \\
\hline & & General Orientation: $75^{\circ}$ & \\
\hline & & Specific Orientation: $390^{\circ}$ & \\
\hline & & Partial removal of vegetation & \\
\hline \multirow{8}{*}{ Plots in location (II) } & \multirow{4}{*}{ II N } & Slope gradient: $35 \%$ & \multirow{4}{*}{++} \\
\hline & & General Orientation: $80^{\circ}$ & \\
\hline & & Specific Orientation: $390^{\circ}$ & \\
\hline & & Natural vegetation & \\
\hline & \multirow{4}{*}{ II T } & Slope gradient: $35 \%$ & \multirow{4}{*}{++} \\
\hline & & General Orientation: $80^{\circ}$ & \\
\hline & & Specific Orientation: $390^{\circ}$ & \\
\hline & & Half removal of vegetation & \\
\hline \multirow{8}{*}{ Plots in location (III) } & \multirow{4}{*}{ III N } & slope: $21 \%$ & \multirow{4}{*}{+} \\
\hline & & General Orientation: $15^{\circ}$ & \\
\hline & & Specific Orientation: $270^{\circ}$ & \\
\hline & & $\mathrm{N}$ vegetation & \\
\hline & \multirow{4}{*}{ III T } & Slope: $21 \%$ & \multirow{4}{*}{0} \\
\hline & & General Orientation: $15^{\circ}$ & \\
\hline & & Specific Orientation: $270^{\circ}$ & \\
\hline & & $\begin{array}{c}\text { Complete removal of vegetation Compaction of the } \\
\text { soil }\end{array}$ & \\
\hline
\end{tabular}

*Notations: +++: Tracer highly visible in the control area of the selected plots, ++: Tracer is visible, +: Tracer more or less visible. 0: no tracer. I N, II N and III N are the non-treated plots, I T, II T and III T are the treated plots.

Specifically, six measuring periods were analyzed and the total amount of rainfall was $173.6 \mathrm{~mm}$. Overland flow occurred in both the plots in five out of the six measuring periods. Actually, overland flow was not observed during the 4th measuring period, when only $1.3 \mathrm{~mm}$ of rain fell in one day. In the other five 
measuring periods small quantities of overland flow were observed and they ranged from 0.7 to $3.3 \mathrm{~mm}$ and from 0.9 to $3.3 \mathrm{~mm}$ in the plots with natural and treated vegetation respectively. The percentages of these quantities on the total amount of rain of the periods ranged from 9.0 to 3.8 and from 11.50 to 3.8 for the two plots respectively. This quantity must have been higher than $3.3 \mathrm{~mm}$ (or $3.8 \%$ ), but it could not be answered how higher it was. Also it is added that during period 4 the total amount of rain was $86.9 \mathrm{~mm}$, it fell in six days and $25 \%, 31 \%$ and $20 \%$ of it fell during three different days respectively. These data support the idea that a very high amount of overland flow than the measured must have occurred on both plots of pair $\mathbf{I}$.

The presentation and the analysis of the data regarding these two plots of pair I indicate that a higher quantity of overland flow occurred in the plot with the treated than with the natural vegetation during the periods of rain. So, if period 4 is excluded, the amount of rain converted to overland flow ranged from 0.7 (period 6 ) to $2.9 \mathrm{~mm}$ (period 7), and from 0.9 (period 6) to $3.2 \mathrm{~mm}$ (period 7) for the plots with the natural and treated vegetation respectively.

The decrease in the range of the percentages is due to the different amount of precipitation corresponding to the measuring periods. Smaller quantities of overland flow occurred in the plots of pair II than those of pair I, despite the removal of higher percentage of vegetation (50\%) in the second pair. This difference can be attributed to the lower inclination of the ground (35\%) of the plots. Overland flow decreased from plot I $\mathbf{N}$ to plot III N.

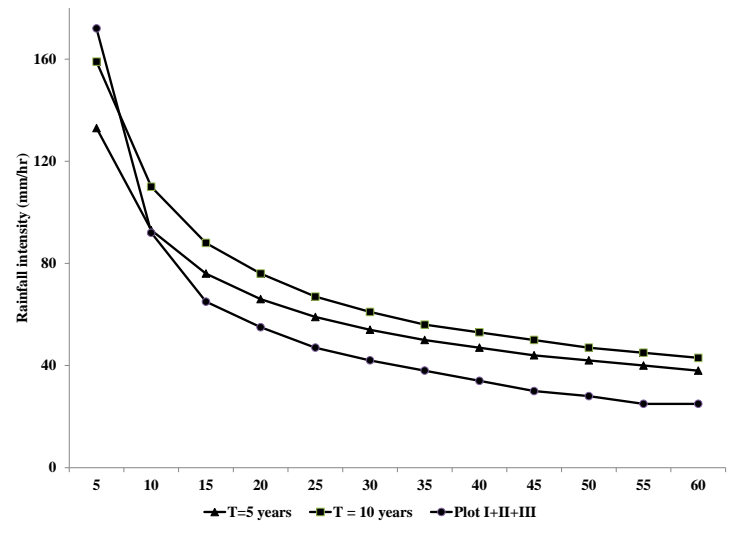

(a)

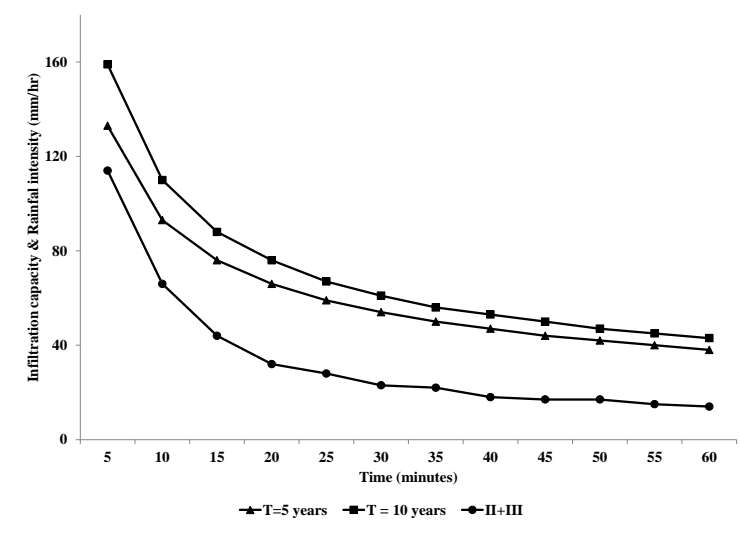

(b)

Figure 1. Comparison of the infiltration capacity of the soil to the estimated rainfall intensities ( $T=5$ and 10 years) for the study area, (a) Plots I, II and III and (b) Plots II and III

The reason for this difference and decrease must have been the different inclination of the ground, because all the other characteristics of the ground were practically the same. The quantities of the collected overland flow were generally small, even from the plot with the higher inclination (50\%) and the maximum of them was $3.3 \mathrm{~mm}(3.8 \%$, in measuring period 3$)$. This quantity must have been higher, if the containers were higher. The treatment of vegetation and the inclination of the ground are not the only parameters that affect the occurrence of overland flow of a site.

\section{Conclusions}

The mean annual rainfall of the study area, calculated for 27 years, is $940 \mathrm{~mm}$ and it ranges from 532 to 1223 $\mathrm{mm}$. A theoretically dry year (amount of annual rainfall lower than $940 \mathrm{~mm}$ ) has a return period of 2 years and a severe drought (amount of rainfall lower by $25 \%$ of the mean value) has a return period of 14 years. 
The distribution of precipitation through the year is extremely uneven and only $6 \%(57 \mathrm{~mm})$ of it falls from May to September. This type of distribution intensifies the water problems in the study area during the summer and the need for rational management of it are evident. The infiltration capacity of the soil in the study area varies from one site to another and it was estimated around 198,120 and $108 \mathrm{~mm} / \mathrm{hr}$ at the end of the first five minutes of the water application. The estimated infiltration capacities are lower than the intensities of rain events with a return period of 5 and 10 years. The application of a tracer on the surface of the ground is a good technique for determining any concurrence of overland flow occurs from rain events with smaller return periods.

\section{Acknowledgement}

This article was funded by the Deanship of Scientific Research (DSR) at King Abdulaziz University, Jeddah. The authors, therefore, acknowledged with thanks DSR for technical and financial support.

\section{References}

Al-Charideh A. (2012), Recharge rate estimation in the Mountain karst aquifer system of Figeh spring, Syria, Environmental Earth Sciences, 65(4), 1169-1178.

Boers M. and Ben Acher J. (1982), A review of rainwater harvesting, Agricultural Water Management, 5, 145 -158.

Brauman K.A., Freyberg D.L. and Daily G.C. (2010), Forest structure influences on rainfall partitioning and cloud interception: A comparison of native forest sites in Kona, Hawaii, Agricultural and Forest Meteorology, 150, 265-275.

Chowdhury A., Jha M.K. and Chowdary V.M. (2010), Delineation of groundwater recharge zones and identification of artificial recharge sites in West Medinipur district, West Bengal, using RS, GIS and MCDM techniques, Environmental Earth Sciences, 59(6), 1209-1222.

Cooley K.R., Brazell L.M. and Fink D.H. (1976), Stock-water harvesting with wax on the Arizona strip, Hydrol. And Water Resources in Arizona and the Southwest, 6, 291-294

Dune T. and Leopold L.B. (1978), Water in environmental planning. W.H Freeman and Company, San Francisco.

Engelhardt I., Rausch R., Keim B., Al-Saud M. and Schuth C. (2013), Surface and subsurface conceptual model of an arid environment with respect to mid- and late Holocene climate changes, Environmental Earth Sciences, 69(2), 537-555.

Fink D.H., Frasier G.W. and Cooley I.C.R. (1980), Water harvesting by wax-treated soil surfaces: progress. Problems and potential, Agriculture Water Management, 3, 125-134.

Frasier G.W. (1980), Water harvesting for livestock, wildlife and domestic uses, Journal of Soil Water Conservation, 35(3), 125-128.

Gehrels J.C. (2000), Recharge assessment: comparing tracers, micro-meteorology and soil water models. In: Sililo O, et al. (eds) Groundwater: past achievements and future challenges. AA Balkema, Rotterdam, 147-152.

Holder C.D. (2004), Rainfall interception and fog precipitation in a tropical montane cloud forest of Guatemala, Forest Ecology and Management, 190, 373-384.

Kyriakakis S. (1993). General information on Crete: Historical background physiographic features, main land-use type and rangelands. In: $7^{\text {th }}$ Meeting of the FAO Sub-network on Mediterranean Pastures and Fodder Crops at Crete in 1993, NI-6. 1988-1993.

Rink K., Kalbacher T. and Kolditz O. (2012), Visual data exploration for hydrological analysis, Environmental Earth Sciences, 65(5), 1395-1403.

Turc L. (1954), Le bilan d'eau des sols: relation entre les précipitations, l'évaporation et l'écoulement. Annales Agronomiques, Série A(5): 491-595.

Udawattage G.N. (1985), The development of micro-catchments in Seri-Lanka, Journal of Hydrology, 80, 351-359. 